\title{
PEDAGOGICAL COMPATIBILITY AS A CONTEMPORARY PROBLEM
}

\section{Abstract}

One of the main problems of contemporary pedagogy is the necessity to consider pedagogical compatibility from a valeological point of view.

It dictates to study the problem of interaction between the teacher and the learner, affect one another's physical and psychological health and maintaining one another's health in the pedagogical process. The article is based on the results of our questionnaire surveys, conversations among teachers, students, and their parents.

The surveys revealed that in some schools still persists the teacher's authoritarianism and intolerance towards pupils. While organizing the pedagogical process, only a small part of teachers emphasized the health requirements of the lesson, most of them did not pay attention to the problem of pedagogical compatibility, in particular, the process of interaction between the student and teacher was not considered from the point of view of the health of both. However, the majority of teachers realize that the quality of their pupils' education, the effectiveness of their work, the motivation of children towards education, ensuring of their creativity and safety at school largely depends on it.

Thus, the question was raised that in the processes of professional education and advanced training of teachers to seriously discuss this problem and provide relevant pieces of knowledge and competencies to the beneficiaries. All of this has prompted the need to enrich the theory of the term "Pedagogical compatibility" and develop a methodological system for its practical implementation. The article defines the essence of the new term "Pedagogical compatibility for health protection". The principles, methods, the pedagogical conditions necessary for its implementation, the model of competences the teacher needs in this field are presented.

Keywords: pedagogical compatibility, principles, methods, competencies of pedagogical compatibility implementation.

\section{Introduction}

One of the main problems of contemporary pedagogy is the organization of health education, the appropriate educational environment, and the maintenance of mutual health 
in the process of teacher-student interaction.

In this context, it is important to study how the teacher's personality and work style influences the learners' health, on the teacher-pupil relationship, on school environment and on atmosphere formation; how students' behaviours affect teacher's health and well-being; whether the teacher is willing and able to eliminate the tension of interpersonal relations, etc. In other words, there is a need to study the issue of pedagogical compatibility in the context of health $[1,105-115]$. It is important to note that over the centuries, throughout the history of the Armenian people, all prominent Armenian educators have addressed the issues of teacher health. In this regard, it is worth mentioning the opinion of the Armenian Diaspora pedagogue of the mid-20 $0^{\text {th }}$ century B. Minasyan, who has been involved in a wide range of educational activities in a number of Armenian communities. He links the teacher's health to having a healthy generation. He said that it is unforgivable to overlook the health of the teacher, also talked about the issues of his overwork and low pay. Considering the teaching field as one of the most difficult and consuming for human health, he demands that the teacher's work be valued properly; improve his social conditions; "ensure the teachers' working period, both old age. "Teachers' special health care has the right to exist because they operate and live in very unfavourable conditions, and if we compare their death to other people's deaths, we can absolutely confirm that teacher deaths from tuberculosis, brain disease and neurasthenia are very high. In addition, teachers are subject to greater degree of the throat and eye diseases, mental and physical deficits, as a result of their profession" [2, 217-218]. "If we want to have a healthy Armenian generation, first of all, we have to worry about the teacher's situation. The Armenian teacher is in a difficult situation both economically and educationally. What do you expect him to give you?" [2, 220]. These thoughts voiced a century ago, are still relevant today.

Our surveys among the teachers showed that the main part of them are overworked today, prone to stereotypical behaviour, are adapted to the situation and do not any longer seek to get out of unfavourable situations. This is certainly a troublesome phenomenon, since long-lasting frustration, "typical to the teacher's activity, may result in the change of his/her personality" [3, 235]. Hence, the teacher, who is physically and psychologically "unhealthy", threatens the pupils' health, on the one hand, but, on the other hand, the "unhealthy" pupil is also "dangerous" for the teacher's health. The pupil does not "obey" psychological influences, defined rules, and if the teacher is not flexible, does not recognize, accept his/her pupil the way he/she is, conflicts arise inevitably and bring stresses to both sides.

All of this also dictates that it is necessary to observe all the phenomena by which 
pupil's and teacher's physical and psychological health is considerably conditioned.

The issue of pedagogical compatibility has been studied by a number of scholars. In particular, with this problem have dealt Russian scholars O.V. Kondratyeva, N. N Obozov, A. L Zhuravlyov, Yu. A. Baluyeva, American psychologist K.E Izard, W. Schutz, Maria Pavles Korres and others. Maria Pavles Korres classified the types of pedagogical compatibility between teacher and learners. highlighted the "social, cultural, linguistic, physical, ethnic nature of pedagogical compatibility". [12]. We would add two more types of compatibility: the psychological and the valeological. Some scholars have outlined the principles that make pedagogical compatibility possible in the teacher-student interaction process. There are emphasized principles of "friendliness, responsibility and mutual principles". Self-esteem and tension are characterized as mechanisms that govern the interpersonal relationship between learner and teacher. "Teacher-student relationships during a pedagogical activity largely depend on the self-esteem of the two and can only be disturbed by tension" [13].

In our opinion, such obstacles can be overcome if the teacher, especially in the classroom, is able to create an atmosphere and relationships where all children feel safe and secure. On the other hand, he will be able to reduce his own tension and put into effect his self-regulation mechanisms. The teacher must be able to express his/her feelings without hesitation, to prevent or resolve conflicts, to balance and control speech and actions, to be direct and sincere with children, to feel the power of his or her pedagogical influence. Some scholars rightly find that an important element is teachers perception. Its "the absence turns the teacher's actions into a stamp, which directly affects on her/his pedagogical activities, speech, language, the rhythm of life, and the daily regime, which is fraught with the risk of losing contact with students and colleagues" [13].

N.N. Obozov raises the problem of the importance of compatibility and coordination of the pedagogical interaction. "In this case, compatibility is seen as an effect of individual co-operation and compliance" [4, 26].

In psycho-pedagogical literature, Russian psychologists approach the classification of compatibility from a structural, functional and adaptive point of view [4, 20]. Compatibility is viewed from the perspective of group training and psychological adjustment. Already is studied the influence of pedagogical communication styles on learner mental activity, the rate and level of intellectual development, personal and professional growth, the proportion of subject interaction features, and effectiveness of educational collaboration and its impact on learning $[5,6,16]$. A typology of learners and educators has been developed based on the concept of "adaptation" [16].

O.V. Kondrateva considers that the psychological types of the teacher's personality 
are a condition for the development of the style of his professional activity [6]. Alahverdova has found that the impact of the compatibility of individuals' action, role and value characteristics depends on the nature of the problem posed to the study group [5] etc. In all of these studies, while it is noted that the phenomenon of compatibility is crucial for enhancing group performance, self-efficacy and group work, there is a lack of theoretical and practical development of teacher-student interoperability in different degrees of learning. American social psychologists view compatibility in the context of behavioural and behavioural approaches. In this respect, it is worth mentioning V. Shutsin, [7, 70], whose demand-line directions are presented in the theory of Personal relations" and K. Izard's approach which found its expression in the theory of "interpersonal attraction" $[8,58]$.

The purpose of this article is: to enrich the theory of the term "pedagogical compatibility" and develop a methodological system for its practical implementation. To achieve this, we have developed the content of the new term "Pedagogical compatibility for health protection", its implementation principles, methods, pedagogical conditions, teacher competencies.

\section{Materials and methods}

To accomplish the goals and objectives of this article, we used analytical-comparative method of pedagogical-psychological analysis of the literature.

We also studied the works of Armenian, Russian and American scholars and online materials on the issues under discussion. In the questionnaire survey participated 600 high school teachers, students and their parents, and 80 teachers were interviewed.

12 math and social science classes in 5 high schools were reviewed to find out the nature and type of pedagogical compatibility; the level and quality of the educational environment, particularly the valeological requirements of the class, the availability of learners' safety and security, the existence of the student-teacher interaction health consciousness: On the basis of all this, it was possible to identify the phenomenon of teacher and student influence on one another's health. We have called the term "Pedagogical compatibility for health protection".

Pedagogical compatibility for health protection is:

$\checkmark$ The psychological, mental, moral and physical harmony between the teacher and the pupil (the subjects of pedagogical activity), the consciousness and readiness to preserve and to care for mutual health, to interact positively on it, as well as it is the complex of the abilities to cooperate on all issues, to make initiatives and joint efforts.

$\checkmark$ The presence of mutual acceptance, understanding, support, positive inclination 
and tolerant behaviour, as well as the mutual knowledge of the goals, values and respect for them. The ability to overcome the problems concerned with school and everyday life, psychological barriers, to solve the risen conflicts together and immediately, to react properly to the new and unexpected situations and to make non-standard but effective joint decisions.

$\checkmark$ The teacher's consciousness and ability to be the child's friend and protector in all situations.

$\checkmark$ The conviction that helping each other and cooperating is a necessity, it is profitable for both of them, and it is the guarantee of their personality development.

The absence of Pedagogical Compatibility may:

- Cause a tense atmosphere in the teacher-pupil relationship, and as a result of which the two sides of the pedagogical process do not feel comfortable and protected, their health is disrupted.

- Weaken the influence of pedagogical activity and lower the level and the quality of pupils' educational, cognitive activity.

- Cause indifference among pupils, loss of interest and motivation towards a certain subject or education in general, even a desire to leave school.

- Cause lack of confidence among teachers towards their own professional skills, even a desire to leave the class or school.

The reasons for Pedagogical incompatibility for health protection may be the following:

- Teacher's emotional consumption.

- Stresses caused by both sides.

- Stresses in the professional field.

- Conflicts with classmates and teachers at school.

- Teacher's disability to solve pedagogical conflicts.

- Lack of teacher's professional competences (as a result of which he/she is not able to prevent, alleviate or solve undesirable phenomena and situations).

- Not accepting, not respecting each other (which results in conflicts, bilateral neuroses, stresses, inappropriate behaviour).

- The absence of learner's self-acceptance (which brings suffering from the thought of not being accepted the way he/she is), etc.

Pedagogical compatibility for health protection will be implemented if the teacher follows these principles of:

- Child's high-value and the consciousness that childhood is unique.

- Child's integrity and providing distinctiveness. 
- Accepting the priority of personality development.

- Dialogue character of pedagogical process and providing subjectivity.

- Pedagogical process focused on healthcare, emotions and values.

The methods to implement Pedagogical compatibility for health protection are the following: personal example, explaining, convincing, talking, substantiating, creating pedagogical situations, the group of cooperative, interactive, dialogue methods of psychological analysis and therapy that bring self-cognition and self-regulation, as well as health technologies / O. S. Gasman, [ 9], [ 10]. V. F. Bazarni [ 11], [ 14]. etc.

Pedagogical conditions that lead to Pedagogical compatibility for health protection are:

1. adopting the principle of the mutual understanding of values in general health subjects of the pedagogical process;

2. striving for succeeding together;

- recognizing, understanding and supporting the child;

- making reasonable compromises;

- maintaining self-control and self-regulation;

- avoiding emotional tension and mutual fear;

- enjoying joint activity;

- making a correct choice and an adequate decision in different situations;

- maintaining a Teacher's high reputation among the pupils;

- supporting a Pupil's desire to cooperate;

3. developing pedagogical activities through dialogue-based formats;

4. mutual understanding of anxieties, fears, verbal and non-verbal signs (gestures, facial expression);

5. mutual tolerance and empathy;

6. maintaining a Teacher's high level of self-cognition and self-regulation, as well as providing pedagogical support to the child so that the latter also reaches the same;

7. defining the forms of effective pedagogical influence, diagnosing the condition of the educational environment and foreseeing, predicting possible consequences, which are all carried out by the teacher;

8. exercising a Teacher's ability to stay away from stresses (adapting to the coauthor role in the child development process, the consciousness that it is necessary to share his/her "own power" with the child, the knowledge of psychoanalytic, psychotherapeutic methods and the ability to implement them);

9. accepting possible negative tendencies in the child development process; 
10. A Teacher's consciousness about the necessity to constantly develop a professional culture of thinking and readiness (information about a child is a continuously developing, newly created, and consistently complementing material);

11. maintaining the atmosphere of mutual help, trust, cooperation and security;

12. creating conditions for mutual freedom, physical and psychological security, as well as for the defence of the rights;

13. organizing the child's involvement in mass activities, listening and responding to the child's voice, opinion (the issues about the child's life, according to his/her age);

14. building a pedagogical process on the basis of reciprocal comprehending and respect;

15. maintaining teacher's restraint, dignity, authority and balance in all situations;

16. bringing forward reasonable demands according to the pupil's abilities;

17. excluding the methods which humiliate human dignity [3, 115-124].

\section{Results}

As a result of the analysis of pedagogical and psychological literature, studies among teachers, students and their parents it was possible to elaborate on the essence of the term "pedagogical compatibility for health protection", the principles of pedagogical compatibility for health protection, the methods, pedagogical conditions necessary for their implementation, state the reasons for pedagogical incompatibility. The conversations with teachers revealed that health-protecting pedagogical compatibility could be implemented:

(a) if the teacher and the student have appropriate competences;

(b) only in the context of interactive pedagogical activities;

c) if the teacher adheres to the ideas and principles of humanistic pedagogy;

d) when the teacher is able to create an appropriate educational environment,

an environment where there is a system of transparent targets, joint exploration of the issues between the teacher and the student, where mutual respect for each other's rights and freedoms are respected.

The dialogue should take place at all levels of value, purpose, content process. In such an environment the needs of the learner to interact with his / her peers through multiple connections and to be able to appear in his / her community are met; They make it possible to accept the influence of the teacher and motivate him to cooperate with the teacher $[15,248]$. 
The analysis of lectures, interviews with professionals and stakeholder surveys allowed us to also characterize and model the competencies needed by the teacher to implement Pedagogical Compatibility for health protection.

The teacher who has competences to implement pedagogical compatibility for health protection is:

Tolerant, this skill is particularly necessary for the teacher. As the children are different, the attitude towards them may also be different. Yet, this attitude must be principally identical: patient, tactful, respectful. Sometimes even own negative feelings should be disguised. Being tolerant does not mean to be generous, all-forgiving, unprincipled or indifferent towards shortcomings, arrogance, cynicism, cheating, betrayal. It does not exclude teacher's demands, complaint and anger. It just requires the discreet expression of them, keeping their own dignity in all situations and loving pupils in all cases.

Nowadays, the term Frustration tolerance is also being used, the manifestation of which is conditioned by the following factors:

a. Presence of goodwill (being focused, organized, discreet, obstinate, decisive, self-restraint, patient) and strong-willed self-control,

b. The flexibility of thinking and behaviour,

c. Communicative skills,

d. Absence of fear towards children,

e. Absence of emotional tension, irritation, indiscretion, imbalance,

f. Enjoying your own activity, workability and moderate tiredness.

Ready for dialogue cooperation. This means that the participants of the pedagogical process (teacher, pupil) accept each other as partners. All the problems, especially those regarding child's life, are solved through dialogues and by getting adjusted to each other, by respecting each other's opinions, taking them into account, as well as by helping each other.

Teacher's excellence is expressed by those questions he/she rises that the child anticipated, yet not always realized, as well as by the way how he/ she is able to formulate the questions the pupil is interested in so that the dialogue between them becomes possible.

By creating an area for dialogue, the teacher admits pedagogical realism, i. e. the unpredictability, uncontrollability of pedagogical process and the endlessness of the child development process. The teacher always seeks ways of communication with a particular child. The teacher never hides his/ her intentions about the children and also learns lessons for himself/herself from any incident or situation.

Transcendental. (knowledge about the own "l"), the reflection of the consciousness to be a source of information for others and to become someone's interlocutor. The teacher 
realizes that it is necessary not only for him/her but also for others to enrich oneself morally, aesthetically, ethically, spiritually and psychologically because this helps to overcome the "Selfish I". The teacher always improves himself/herself, is always in search and obsessed with the job. It is important for him/her not to glow with multiple skills in front of the pupils but to get new knowledge in order to be able to help the children to solve their problems together.

Coincident skill. readiness to cooperate and to reach an agreement, knowledge about and implementation of own social roles and functions, being open to the interlocutor, a principled position not to hide anything, self-recognition, self-regulation, understanding own psychological processes, never hiding real feelings, all-knowing, above reproach, the presence of the proficiency not to seem an important person and the conviction that "The children rapidly differentiate which teacher loves them really and which one pretends."

Constructive behaviour. experience to overcome contradictions, to solve the conflicts on a constructive, free of violence basis, understanding the peculiarity and diversity of internal and external, invisible and visible conflicts that are conditioned by some children's development particularities, by the type of school subject, as well as by cooperation situations among one another, teachers, parents and themselves.

Is ready for joint activity. has the experience to cooperate with others and to solve the problems together, is able to infect children with his/ her values, to choose common goals and concepts, to accept each other and to create an internal positive attitude towards each other. Joint activity is defined for the teacher not by the person's group status but by the desire and ability to make joint efforts, to participate in cooperative work, to perceive own life in the context of "common life", to work in a team and cooperate, as well as by the quality to accept oneself as a part of all.

Reflectivity. A person who praises human concepts and is obsessed with the highest level of self-devotion to the profession. For such a person, doing good is a vital need. Such a pedagogue can penetrate the depths of child's life, realizes the necessity to get to know the child, to perceive, to support the latter, knows that all this requires serious mental work and psychological tension, as well as comprehends that everything is possible only in case of sympathy and identification. This teacher always looks back and returns to the work already done, is able to analyze critically the job made by him/her, to find the deficiencies, strong and weak points and to take relevant measures, solutions.

A child's rights defender. Struggles for the child's voice to be heard, for the child's opinion to be taken into account in all life situations and for solving the problems in favour of, for the sake of the children and with their participation.

An example of a healthy lifestyle. The teacher is guided by the rules of a healthy 
lifestyle, infects the children with this concept, gives them knowledge about it, as well as skills to practice.

Realizes his/her role of co-creator. The teacher is ready to share the "power" with the child and accepts the concept that it is the child who creates the teacher.

Masters the latest pedagogical technologies and methods. Particularly, mastering the methods of self-cognition, self-regulation, self-esteem, self-discovery, the technologies to get to know, to understand and to support the child (cooperative teaching, equal to equal teaching, pedagogical support, project method, etc.)

\section{Discussion}

The results of studies conducted among the teachers, students and their parents proved that today the problem of protecting the health of students and teachers remains an important issue in the organizing process of education. It depends on

- the need for a healthy and free society,

- ensuring the quality of education,

- generating positive motivation for students to study,

- developing a sense of safety and security among students,

- implementation of teacher and student joint goals.

The discussions on the main points of the article held among the lecturers, masters, post-graduate students and young scientists of the Armenian State Pedagogical University and in pedagogical councils of 5 schools confirm that developments on the content of the new term "Pedagogical compatibility for health protection" and the methodological system for its implementation will contribute to the solution of the problem of valeologization of the educational environment.

Table 1.

The model of the teacher's competencies needed to implement pedagogical compatibility for health protection.

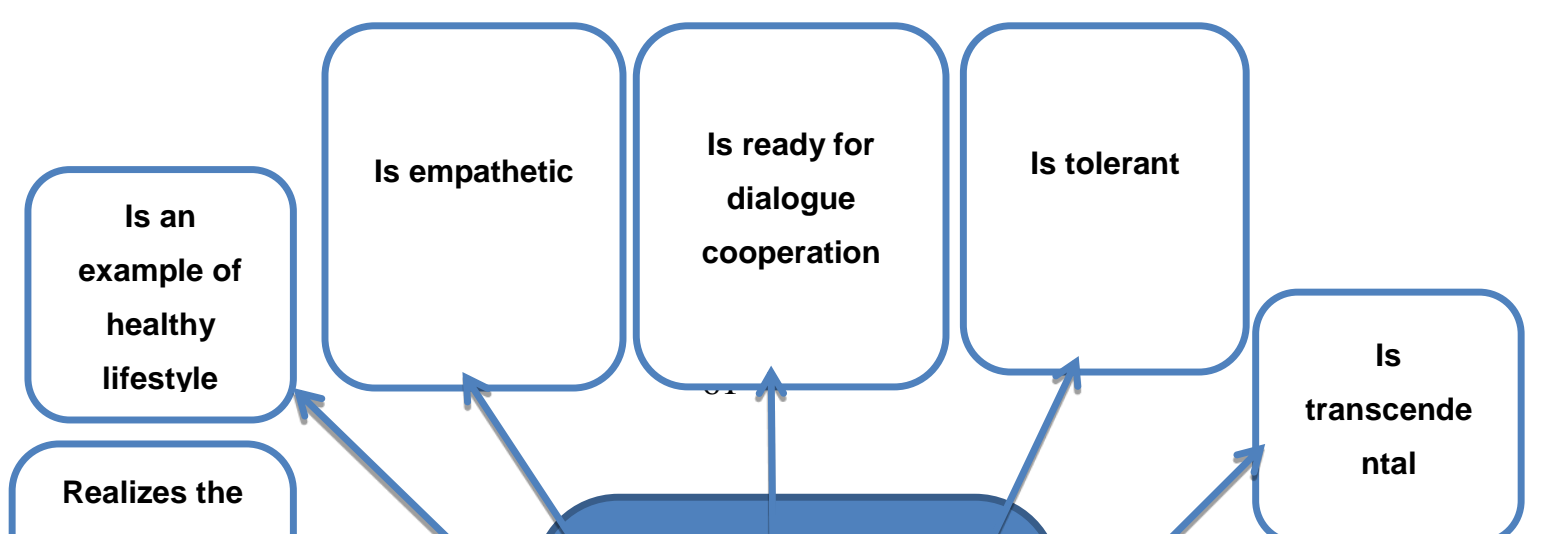




\section{Conclusions}

Thus, in this article, pedagogical compatibility is considered from a health care perspective, in the context of the mutual care of the teacher and learner. Today it is indisputable that the quality of education, the positive motivation of learners to learn, the development of a sense of safety and security among learners, largely depends on the level of pedagogical process's key actors- in teacher and learner health compatibility level.

Maintaining the health of both the educator and the learner is not just their personal problem. It is the key to ensuring the security of each country. A physically and mentally "unhealthy" teacher threatens the health of students. On the other hand, an "unhealthy" student is also "dangerous" for the teacher's health.

Developed materials, in particular, the definition of the term "Pedagogical compatibility for health protection", identification of pedagogical incompatibility and its causes, principles, methods, conditions, implementation of pedagogical compatibility, competencies needed by the teacher can be useful to current teachers of primary school, parents, bachelors, masters, and postgraduates, lecturers teaching general and Theoretical Pedagogy. 


\section{References}

\section{Books}

Topuzyan A. \& others (2017). "Pedagogical Health Science in Elementary Education". Methodological manual, NAS RA, 171 pages

Minassian, B. (1931). Fundamentals of Pedagogy. Tabriz. 450 pages.

Gevorgyan S., Hovhannisyan A. \& others (2014). Psycho-pedagogical Dictionary. author Publisher, Yerevan. 261 pages.

Obozov, N. (2001). Tipi lichnosti, temperament i kharakter. Sankt-Peterburg. 40 st.

Allakhverdieva, O. (2017). Peregavori v socialnoy rabote. Uchebnoe posobie. SPBSPBGU. 134 str.

Kondratieva O. (1996). Psikhologicheskie tipi, lichnost uchiteley kak uslovie formirovaniya profesionalnovo stilya dejatelnosti. Diss.kand. psikh. nauk, N.Novgorod.

Shutts V. (2008). Glubokoe prostata. Osnovi jiznennoy filosofii Azbuka-klassika. M. 244 st. Izard K. (2006). Emocii cheloveka, Moskva 311 st.

Gazman O. (1990). Gumanizm i svoboda: gumanizaciya vospitaniya v sovremennikh usloviyakh, Moskva, 137 st.

Mikhaylova N. i drugie, (2006). Pedagogicheskaya podderjka rebyonka v obrazovanii, Moskva, 207 st.

Bazarni V. (1995) Ekspress-diaknostiki dinamiki psikhosensornovo funkcionalnovo I fizicheskovo razvitiya uchashchikhsya, Sergiev Posad, 151 st.

\section{Web Pages}

https://www.researchgate.net/figure/Types-of-compatibility-between-educator-and-

learner fig1 220363407

https://vikidalka.ru/2-38461.html

Journals

Dikhan L. (2002). Usloviya valeologizacii obrazovatelnoy sredi shkolnikov. Valeologiya N 2, M.

Kodjaspirova G. (2005). Pedagogicheskaya antropologiya. Gardariki, Moskva, 284 st.

Kondratiev S. (2003). Psikhologicheskie tipi uchiteley i studentov. Psikhologicheskaya nauka i obrazovanie, N 3 (s. 52-57), Moskva. 